\title{
Frequency Domain Causality Analysis of Interactions between Financial Markets of Turkey
}

\author{
Mustafa Ozer ${ }^{1} \&$ Melik Kamisli ${ }^{2}$ \\ ${ }^{1}$ Faculty of Economics and Administrative Sciences, Anadolu University, Eskişehir, Turkey \\ ${ }^{2}$ Department of Banking and Insurance, Bozüyük Vocational School, BilecikŞeyh Edebali University, Bilecik, \\ Turkey \\ Correspondence: Melik Kamisli, Department of Banking and Insurance, Bozüyük Vocational School, Bilecik \\ Şeyh Edebali University, Bilecik, Yeşilkent Mahallesi 1036 Sokak, Bozüyük, 11300, Turkey. Tel: \\ 90-228-214-1111. E-mail: melik.kamisli@bilecik.edu.tr
}

Received: November 2, 2015

Accepted: December 15, $2015 \quad$ Online Published: December 25, 2015

doi: 10.5539/ibr.v9n1p176

URL: http://dx.doi.org/10.5539/ibr.v9n1p176

\begin{abstract}
In this paper, we examined the dynamic linkages between financial markets of Turkey by using frequency domain causality analysis, proposed by Breitung and Candelon (2006), for the weekly Turkish data from 2003 to 2015. The results show that there are volatility spillovers from stock market returns to interest rate and EURO both in the mid and long terms, and short and medium-terms to U.S. Dollar; but, from U.S. Dollar to stock market returns in the short-term. In the long-run, EURO exchange rate Granger cause to interest rate; but, interest rate Granger cause to EURO exchange rate in the short-run. On the other hand, there is no evidence of volatility spillovers from EURO and interest rate to stock market returns. Based on these results, we can conclude that there are certain degree of interdependence and volatility spillovers among the financial markets of Turkey, which have serious policy implications.
\end{abstract}

Keywords: frequency domain causality, traditional Granger causality, volatility spillovers

\section{Introduction}

Following 2001 Crisis, Turkey has been considered as one of the leading emerging financial markets on which international investors and financial market professionals have focused their attention and has become investment icon in the global financial markets, since Turkey has been one of the leading country that provided profitable investment opportunities to foreign investors. In this development, policies, such as liberalization of foreign capital accounts and adoption of more flexible exchange rate regimes that implemented in early 1980s have played crucial role. Along with these factors and emergence of new also increased the interest of academicians, policy makers and professional investors in studying the interactions between financial markets within and across countries. On the other hand, even though the liberalization of foreign capital controls in emerging markets, especially in Turkey, has opened the possibility of international investment and portfolio diversification, it is also true that the adoption of more flexible exchange rate regimes by these countries has contribute to increase the volatility of foreign exchange markets and the risk associated with such investments. For example, as Rahman and Uddin (2009) pointed out, the interactions between stock prices and exchange rates have been seen crucial by the academicians, market professionals and policy makers, since they both create significant effects on the development of a country's economy. Also, we know that fundamentalist investors often use the relationships between stock prices and foreign exchanges to predict the future trends for each variables. Moreover, since the currency is included as an asset in the portfolios of professional investors, managers of these institutions might benefit from the information about the direction and sign of the causal relationship between exchange rates and stock prices to manage risks efficiently. Finally, allowing the free flows of capital has created investment opportunities for multinational corporations especially in emerging countries.

To understand properly the nature and the direction of the causality between these two important variables, first we have to understand theoretical explanations of the relations between two. There are two alternative explanations of the relationships between exchange rates and stock prices. These are the traditional and portfolio approaches. According to the traditional approach, because of the depreciation of the domestic currency, local firms become more competitive and they increase their exports. The rising exports of these firms can contribute 
to rise in their profits and to increase in stock prices in the short run, because the rising competitiveness of the firm's exports causes changes in the value of the firm's assets and liabilities, implying a positive correlation between exchange rates and stock prices. Therefore, according to the traditional approach, changes in exchange rate should lead to changes in stock prices. On the other hand, the portfolio balance approach stresses on the role of capital account transaction. According to the portfolio balance approach, an increase in stock prices causes investors to increase their demand for domestic assets and thus causes an appreciation in the domestic currency, which implies an inverse relationship between two and that stock prices can lead exchange rates. Also, as is indicated Kutty (2010), since a decrease in the stock prices will result in decrease in corporate wealth and the country's wealth as well, there might be a fall in the demand for money and monetary authorities will reduce the interest rates to offset the effects of this situation. When interest rates are relatively lower than that of the world, there will be sudden reversal of capital to take advantage of higher rates of return in other part of the world, possible leading to currency depreciation.

The empirically many economists have provided the evidence of significant relationship between exchange rates and stock prices. But, their results are mixed in terms of the sign and direction of causality between exchange rates and stock prices. The studies of Giovannini and Jorion (1987), Solnik (1987) and Smith (1992) indicate that there is significant positive relationship between exchange rates and stock prices. On the other hand, the results of the studies of Muhammad and Rasheed (2002), Bhattacharya and Mukherjee (2003), Rahman and Uddin (2009) provided evidences of negative relationship between exchange rates and stock prices. The studies of Bahmani-Oskooee and Sohrabian (1992), Kumar (2010), Andreou et al. (2013) and Mozumder et al. (2015) established bidirectional relationship, whereas that of Abdalla and Murinde (1997), Kanas (2000), Mishra (2004), Morales (2008), Fedorova and Saleem (2010), Walid et al. (2011), Alagidede et al. (2011) and Bonga-Bonga and Hoveni (2013) indicate unidirectional relationship. Finally, the studies of Ong and Izan (1999) and Nieh and Lee (2001) concluded that there is no empirical relationship between exchange rates and stock prices.

There is a common believe among the economists that stock exchange and interest rate should be considered as two critical determinants of economic growth. The effects of interest rate on stock exchange provide important implications for policies towards financial markets, mainly including monitory policy, risk management practices and government policy. As indicated by Wongbangpo and Sharma (2002), the interest rate volatility is one of the critical factor for asset pricing, since interest rate is used as a discount rate to compute the present values of asset prices. Thus, we can expect an inverse relationship between interest rates and stock prices. Also, as is pointed out by Mok (1993) and Ma and Kao (1990), one would expect an inverse causality running from interest rates to stock prices, since a rise in the interest rate reduces the present value of future dividend's income, which will put downward pressure on stock prices. A rise in the nominal interest rate will affect investors' decisions on asset holdings and can cause reallocation their capital from stock market to money market. Also, an increase in interest rates can cause a decrease in corporate profitability, since an increase in interest rates can lead to a recession which causes a decline in future corporate profitability and rises the financing costs. As mentioned by Wongbangpo and Sharma (2002), the higher interest rates have a potential to create discouraging effects on mergers, acquisitions and buyouts. It is a well-known fact that low interest rates lead to lower opportunity cost of borrowing, stimulate investments and economic activities which could increase stock price. According to studies of Harasty and Roulet (2000), Wong et al. (2005) there is a long-run relationship between interest rates and stock prices. The studies of Campbell (1987), Shanken (1990), Arango et al. (2002) and Alam and Uddin (2009) indicate an inverse relation between interest rates and stock prices. The results of the study of Hashemzadeh and Taylor (1988) provide some evidence of causality running from interest rate to stock prices in U.S. financial markets. But, Mukherjee and Naka (1995)'s findings indicate a positive relationship between stock price and interest rate on demand deposit in Japan.

As Choi and Park (2008) mentioned, according to traditional wisdom, there is a need to increase interest rates in the middle of a currency crisis to stabilize the foreign exchange market. Also, high interest rates are required in achieving reversal of currency undervaluation after a currency crisis. In the short-run, higher interest rates can be helpful to reduce the size of capital outflows by increasing the cost of currency speculation and attracting capital inflows by making domestic assets more attractive. On the other hand, in the long-run, they contribute to improvement in current account balance by reducing domestic absorption. Thus, the IMF rescue packages for Turkey and Asian countries use tight monetary policy together with financial and corporate restructuring.

According to Hacker et al. (2012), one would expect a negative or positive relationship between exchange and interest rates. A rise in a country's interest rate can cause portfolio reallocations leading to appreciation of the country's currency, since the country's interest bearing assets become more attractive. As the country's interest bearing assets become more and more attractive, investors will react to purchasing more of those assets which 
result in appreciation of that country's currency as has been the case for Turkey since 2002 mostly. As pointed out in Hamrita and Trifi (2011), according to the parity conditions, there is an inverse relationship between the interest rate and the exchange rate. On the other hand, as mentioned in Ma and Kao (1990) and Hacker et al. (2012), due to Fisher hypothesis, one can justify a positive relation between exchange rate and interest rate. According to Fisher hypothesis, ceteris paribus, a rise in a country's nominal interest rate should be matched by a rise in the expected percent change in the exchange rate. Also, a higher exchange rate can contribute to reduce the country's trade deficits. Along with sticky-prices in the short-run, a rise in exchange rate will cause an increase in interest rates because of rising aggregate demand resulted in rising exchange rate.

Studies of Ghosh and Phillips (1998) and Baig and Goldfajn (2002) didn't produce significant negative association between interest rates and exchange rates, they provided some evidence of negative significant relations for some subsample periods. Dekle et al. (2002) provided evidence of Granger causality running from interest rates to exchange rates during the crisis period for countries in the sample. According to Park et al. (1999) there is a bidirectional causality between nominal exchange rates and interest rates during the crisis period of September 1997-September 1998 in Korea. Chinn and Meredith (2004) found a positive relationship between interest rates and exchange rates for the G-7 countries for the long-maturity data and negative relationship between them when using short-maturity data. Choi and Park (2008) provided the evidence of the causal relationship between interest rates and exchange rates during the Asian crisis.

There are some reasons that need to be mentioned why this study has been done. First of all, even though there is a large body of literature examines the relationship between stock prices, interest rates and foreign exchange rates in developed as well as in developing countries, it is hard to say that there is a consensus regarding on sign and direction of the relationship between these variables. Especially, disagreements exist among economists and policy makers as to whether which financial variable Granger cause the other or vice versa. These disagreements make the study of dynamic linkages between financial markets of Turkey interesting and challenging. Secondly, most of the studies that examines the relationships between these variables use traditional definition of Granger causality, which provides only one overall picture of the relationships. By using frequency domain approach, we will first attempt to disentangle volatility spillovers between Turkey's financial markets into different periods such as short, medium and long runs. Finally, Turkey's financial markets and interactions between them have been getting a lot of attentions of both international investors and academicians, since Turkey's financial markets have been offering relatively high rate of returns than that of others. Also, as indicated in Özer (2015), the capital inflows have been the key factor in developments in Turkey's economy especially after 2001 Crisis.

Therefore, in this paper, we analyze the volatility spillovers between Turkish financial markets closely by using the frequency domain Granger causality approach developed by Breitung and Candelon (2006). Therefore, in section 2, we explain the method and data used in the study fully. The rest of the paper is organized as follows. Section 3 presents the results of the study and section 4 concludes.

\section{Methodology and Data}

In traditional Granger causality testing approach, the prediction errors are obtained by a model that relates $\mathrm{Y}$ to past and current values of both $\mathrm{X}$ and $\mathrm{Y}$. This method has been widely used because the test is simply carried out to determine whether the coefficients of the regression model, associated with past and current values of $X$, are significant. To investigate the linear Granger causality between two variables $\mathrm{X}$ and $\mathrm{Y}$, a p-order linear vector autoregressive model, $\operatorname{VAR}(\mathrm{p})$, is estimated:

$$
\left[\begin{array}{l}
X_{t} \\
Y_{t}
\end{array}\right]=\left[\begin{array}{l}
\alpha_{1} \\
\alpha_{2}
\end{array}\right]+\left[\begin{array}{ll}
\emptyset_{11,1} & \emptyset_{12,1} \\
\emptyset_{21,1} & \emptyset_{22,1}
\end{array}\right]\left[\begin{array}{l}
X_{t-1} \\
Y_{t-1}
\end{array}\right]+\cdots+\left[\begin{array}{ll}
\emptyset_{11, p} & \emptyset_{12, p} \\
\emptyset_{21, p} & \emptyset_{22, p}
\end{array}\right]\left[\begin{array}{l}
X_{t-p} \\
Y_{t-p}
\end{array}\right]+\left[\begin{array}{l}
\varepsilon_{1 t} \\
\varepsilon_{2 t}
\end{array}\right]
$$

where $\varepsilon_{t}=\left(\varepsilon_{1 t},\right)^{\prime}$ is a vector of white noise processes with a non-singular covariance matrix $\Sigma_{\varepsilon}$.

By carrying out either an F-test (restricted versus unrestricted) or Wald-type test, one can find alternative causal relations between $\mathrm{X}$ and $\mathrm{Y}$. But, since all these Granger causality tests are providing only one statistics for the whole sample, it is not well suited to distinguish short and long run effects. Thus, as mentioned in Joseph et al. (2015), this type of Granger causality tests unfortunately do not indicate causality in its conventional sense, since they only measure precedence and information content. Even though sign and the direction of causality can differ between frequency bands (Granger \& Lin, 1995), the traditional Granger causality tests are unable to diagnose these. Because of these reasons, as is suggested in Ding et al. (2006), to obtain a more precise picture of the short, medium and long run Granger causality, a frequency domain Granger causality test should be used.

Even though frequency domain approach to causality testing has been developed and used recently, according to Croux and Reusens (2013), the concept of Granger causality in the frequency domain is not new and was 
originally proposed by Granger in 1969. Later, Geweke (1984) proposed a measure for this Granger causality in the frequency domain which allows to perform the causality tests at different frequencies not causing any loss of explanatory power. Geweke's measure of causality $\left(M_{Y \rightarrow X}\right)$ can be decomposed as follows (Kratschell and Schmidth, 2012):

$$
M_{Y \rightarrow X}=\frac{1}{\pi} \int_{0}^{\pi} f_{Y \rightarrow X}(\omega) d \omega
$$

To test the existence of Granger causality at a given frequency, several researchers developed different test producers. First of all, Geweke (1984) proposed a Wald-test that imposes linear restrictions on the parameters. Secondly, this test procedure was further extended by Breitung and Candelon (2006). Thirdly, Yao and Hosoya (2000) developed an alternative Wald-type test which is based on non-linear restrictions on the VAR parameters. Finally, Seth (2010) discussed tests based on bootstrap and permutation resampling techniques.

In this paper, we use the method developed by Breitung and Candelon (2006). Breitung and Candelon (2006) procedure decompose the total spectral interdependence between the two series into a sum of "instantaneous", "feed forward" and "feedback" causality terms. To explain Breitung and Candelon approach, we will use a finite-order vector autoregressive (VAR) representation of the two time series, $\mathrm{X}_{\mathrm{t}}$ and $\mathrm{Y}_{\mathrm{t}}$, is the following form:

$$
\Theta(L)\left(\begin{array}{l}
X_{t} \\
Y_{t}
\end{array}\right)=\left(\begin{array}{ll}
\Theta_{11}(L) & \Theta_{12}(L) \\
\Theta_{21}(L) & \Theta_{22}(L)
\end{array}\right)\left(\begin{array}{l}
X_{t} \\
Y_{t}
\end{array}\right)=\left(\begin{array}{l}
\varepsilon_{1 t} \\
\varepsilon_{2 t}
\end{array}\right)
$$

where $\Theta(L)=1-\Theta_{1} L-\Theta_{2} L^{2}-\cdots-\Theta_{p} L^{p}$ is a lag polynomial with $L^{j} X_{t}=X_{t-j}$ and $L^{j} Y_{t}=Y_{t-j}$. It is assumed that the error vector $\varepsilon_{t}=\left(\begin{array}{lll}\varepsilon_{1 t} & \varepsilon_{2 t}\end{array}\right)^{\prime}$ is multivariate white noise with $E\left(\varepsilon_{t}\right)=0$ and $E\left(\varepsilon_{t} \varepsilon_{t}^{\prime}\right)=\Sigma$, where $\Sigma$ is positive definite and symmetric.

When $\mathrm{G}$ is a lower triangular matrix and $\mathrm{G}^{\prime}$ is an upper triangular matrix of the Cholesky decomposition, $G^{\prime} G=\Sigma^{-1}$ such that $\mathrm{G} \varepsilon_{t}=\eta_{t}$ and $E\left(\eta_{t} \eta_{t}^{\prime}\right)=I$. Based on this Cholesky decomposition, we can write the MA representation of system as follows:

$$
\left(\begin{array}{c}
X_{t} \\
Y_{t}
\end{array}\right)=\left(\begin{array}{ll}
\psi_{11}(L) & \psi_{12}(L) \\
\psi_{21}(L) & \psi_{22}(L)
\end{array}\right)\left(\begin{array}{l}
\eta_{1 t} \\
\eta_{2 t}
\end{array}\right)
$$

where $\psi(L)=\Theta(L)^{-1} G^{-1}$ and $\left(\eta_{1 t} \eta_{2 t}\right)^{\prime}=\mathrm{G}\left(\varepsilon_{1 t} \varepsilon_{2 t}\right)^{\prime}$, so that $\operatorname{cov}\left(\eta_{1 t}, \eta_{2 t}\right)=0$ and $\operatorname{var}\left(\eta_{1 t}\right)=\operatorname{var}\left(\eta_{2 t}\right)=1$. When we use the Fourier transformation to system, following spectral density of $X_{t}$, which has the two parts, will be obtained:

$$
f_{X}(\omega)=\frac{1}{\pi}\left\{\left|\psi_{11}\left(e^{-i \omega}\right)\right|^{2}+\left|\psi_{12}\left(e^{-i \omega}\right)\right|^{2}\right\}
$$

According to Kratschell and Schmidth (2012), the first component in equation (5) is called "intrinsic" term, which is driven by past shocks in $X_{t}$ and the second element is called "causal" term $\left(\psi_{12}\left(e^{-i \omega}\right)\right)$ of the spectrum, which contains the predictive power of the variable $Y_{t}$ and is used by Breitung and Candelon (2006) to construct their frequency domain Granger causality test. To call that $Y_{t}$ does not "Granger cause" $X_{t}$ at frequency $\omega$, the predictive component of the spectrum of $X_{t}$ at frequency $\omega$ must be zero. This leads to the measure of causality suggested by Geweke (1984) and Hosoya (2001) and expressed as:

$$
\begin{aligned}
M_{Y \rightarrow X}(\omega) & =\log \left[\frac{2 \pi f_{X}(\omega)}{\left|\psi_{12}\left(e^{-i \omega}\right)\right|^{2}}\right] \\
& =\log \left[1+\frac{\left|\psi_{12}\left(e^{-i \omega}\right)\right|^{2}}{\left|\psi_{11}\left(e^{-i \omega}\right)\right|^{2}}\right]
\end{aligned}
$$

If $\psi_{12}\left(e^{-i \omega}\right)=0$, then, $M_{Y \rightarrow X}(\omega)$ will be zero and we will conclude that $\mathrm{Y}$ does not Granger cause $\mathrm{X}$ at frequency $\omega$. Therefore, the equation of $\psi_{12}\left(e^{-i \omega}\right)=0$ should be considered as a condition for no Granger causality at frequency $\omega$.

The null hypothesis for testing $\mathrm{Y}$ does not Granger cause $\mathrm{X}$ within a bivariate framework based on Geweke measure is expressed as follows:

$$
H_{0}: M_{Y \rightarrow X}(\omega)=0
$$


Following Breitung and Candelon (2006), to test the null hypothesis of Y does not Granger cause X at frequency $\omega$, we will simplify the above condition to a set of linear restrictions on the coefficients of the first component of the VAR model in equation (3):

$$
X_{t}=\Theta_{11,1} X_{t-1}+\cdots+\Theta_{11, p} X_{t-p}+\Theta_{12,1} Y_{t-1}+\cdots+\Theta_{12, p} Y_{t-p}+\varepsilon_{1 t}
$$

where $\Theta_{11, j}$ and $\Theta_{12, j}$ are the coefficients of the lag polynomials $\Theta_{11}(L)$ and $\Theta_{12}(L)$. As stated in Croux and Reusens (2013), the necessary and sufficient set of conditions for no Granger causality at frequency $\omega$ is given by following equations:

$$
\begin{aligned}
& \sum_{j=1}^{p} \Theta_{12, j} \cos (j \omega)=0 \\
& \sum_{j=1}^{p} \Theta_{12, j} \sin (j \omega)=0
\end{aligned}
$$

We use a standard F-test on a set of coefficients of equations (10) and (11) to test the null hypothesis of no Granger Causality at frequency $\omega$. F-statistic is approximately distributed as $F(2, T-2 p)$ for $\omega \epsilon(0, \pi)$, where 2 is the number of restrictions and $\mathrm{T}$ is the number of observations used to estimate the VAR model of order $\mathrm{p}$. The null hypothesis in this test, which corresponds to the null hypothesis tested by Geweke, $M_{Y \rightarrow X}(\omega)=0$, is

$$
H_{0}: R(\omega) \Theta_{12}(L)=0
$$

with

$$
R(\omega)=\left[\begin{array}{llll}
\cos (\omega) & \cos (2 \omega) & \ldots & \cos (p \omega) \\
\sin (\omega) & \sin (2 \omega) & \ldots & \sin (p \omega)
\end{array}\right]
$$

According to Kratschell and Schmidth (2012), an important step in this method is to determine the lag order of the VAR, since it determines the dynamic structure of the model. Also, to analyze the frequency domain Granger causality within cointegrating framework, we need to replace $\mathrm{X}_{\mathrm{t}}$ by $\Delta X_{t}$ in equation (9) leaving the right hand side of the equation unchanged. As mentioned in Tiwari (2012), in cointegrated systems the definition of causality at frequency zero should be considered as equivalent to the concept of "long-run causality". On the other hand, in stationary framework there won't be any long-run relationship between the time series.

In order to investigate the dynamic interactions between financial markets of Turkey, we use weekly data for interest rates (IR), exchange rates (ER) and stock prices (SP), which are retrieved from DataStream, covering the sample period from 2003-2015. The end-of-week stock index used in this study is ISE-30 indices (ISE). The exchange rates data are end-of-period nominal exchange rates, expressed in Turkish Lira per U.S. Dollar and EURO and interest rate is the interbank interest rate. Following the suggestion of Arouri et al. (2011), we prefer to use weekly data because weekly data appear to capture the interactions among financial markets.

\section{Empirical Results}

We first start interpreting the some descriptive statistics for the stock market returns, interest rates and exchange rates for Turkey. Table 1 presents some summary statistics for the variables.

Table 1. Summary of descriptive statistics

\begin{tabular}{lcccc}
\hline & SP & USD & EURO & IR \\
\hline Mean & 0.0007 & 0.0001 & 0.0002 & 14.38 \\
Median & 0.0010 & -0.0004 & -0.0002 & 13.49 \\
Maximum & 0.1273 & 0.0704 & 0.0477 & 46.29 \\
Minimum & -0.1359 & -0.1194 & -0.0677 & 2.02 \\
Std. Dev. & 0.0197 & 0.0084 & 0.0081 & 9.05 \\
Skewness & -0.1721 & -0.0719 & 0.4181 & 1.67 \\
Kurtosis & 6.94 & 21.37 & 8.99 & 6.04 \\
Jarque-Bera & $1955^{*}$ & $42173^{*}$ & $4574^{*}$ & $2548^{*}$ \\
ARCH-LM & $79.58^{*}$ & $72.53^{*}$ & $115.71^{*}$ & $685.71^{*}$ \\
\hline
\end{tabular}

According to results in Table 1, all financial variables have positive mean returns. While Stock returns and USD have negative skewness, interest rates and EURO return have positive skewness. All series have excess kurtosis values and all kurtosis coefficients are significantly greater than three. Thus, all series have heavy tails relative to the normal distribution, which is typical for the financial variables. Skewness and kurtosis values of stock market 
returns and USD indicate that the distributions of these variables are negatively skewed and leptokurtic. Also, these findings imply that these series have typically asymmetric distributions. As a result, the Jarque-Bera test statistics (JB) indicate that all series do not have normal distribution. Finally, all ARCH-LM test results indicate that there are significant ARCH effects in all variables in the study implying that volatility spillovers between financial variables can be modelled by employing ARCH/GARCH models.

As mentioned in Ciner (2011a), one can use the second moment of the return distributions in analyzing the dynamic linkages between exchange rate, stock prices and interest rate. Due to the study of Ross (1989), the volatility is considered as a proxy for the rate of information flow in markets. Thus, one can also derive further information regarding the dynamic linkages between financial markets by using the results. As we mentioned in introduction, understanding volatility spillovers can be important for academicians, policy makers and professional investors.

Because of the reasons stated in Ciner (2011a), we obtain the volatilities of each variable by using $\operatorname{GARCH}(1,1)$ model with t-distributed errors. And then, we use these volatilities to construct bivariate VAR models to determine the direction of causal relationships between interest rates, exchange rates and stock prices. We use VAR Granger causality tests performed as Wald tests, as a starting point of our empirical analysis. Table 2 reports the results of both traditional and frequency domain Granger causality tests.

Table 2. Traditional and frequency domain Granger causality test results

\begin{tabular}{lccccccc}
\hline & Traditional & \multicolumn{7}{c}{ Frequency-domain } \\
\cline { 3 - 8 } & & \multicolumn{2}{c}{ Long Term } & \multicolumn{2}{c}{ Medium Term } & Short term \\
\hline SP -> EURO & $17.82^{* *}$ & $6.15^{*}$ & $6.13^{*}$ & 2.70 & $6.64^{*}$ & 4.27 & 3.56 \\
EURO -> SP & 5.32 & 1.198 & 1.192 & 2.977 & 2.151 & 0.885 & 1.059 \\
SP -> IR & $9.69^{* *}$ & $9.471^{*}$ & $9.471^{*}$ & $6.288^{* *}$ & 1.342 & 0.593 & 1.704 \\
IR -> SP & 1.18 & 0.209 & 0.208 & 0.113 & 0.510 & 0.806 & 1.118 \\
SP -> USD & $16.99^{* *}$ & 2.87 & 2.81 & 0.99 & $7.95^{*}$ & 3.71 & $6.11^{*}$ \\
USD -> SP & 3.29 & 1.06 & 1.08 & 1.22 & 0.79 & $7,61^{*}$ & 0,88 \\
IR -> EURO & $14.80^{* * *}$ & 2.88 & 2.89 & 3.77 & 0.44 & $8.20^{* *}$ & 4.69 \\
EURO -> IR & 12.72 & $9.80^{*}$ & $9.80^{*}$ & 2.75 & 0.27 & 0.10 & 1.90 \\
USD -> IR & & \multicolumn{7}{c}{ No significant model } & & \\
IR -> USD & & \multicolumn{7}{c}{ No significant model } \\
\hline
\end{tabular}

Based on the results of traditional Granger causality tests shown in Table 2, the stock prices Granger cause both EURO and U.S. Dollar exchange rates and interest rates. Also, interest rates Granger cause EURO exchange rate. But the results do not indicate any causality running from exchange rates to stock prices, interest rates to stock prices, and EURO exchange rates to interest rates. Therefore, it is fair to conclude that the results of traditional causality tests mostly provide evidence of supporting the portfolio balance approach, as oppose to traditional approach.

Classical Granger test results that we discussed above do not provide clear evidence whether the co-movements depend on short-run fluctuations or longer cycles. In other words, according to Ciner (2011b), this test procedure produces a single, one-shot statistic regarding predictability and implicitly and ignore the possibility that causal relationships between variables could change across different frequencies. Thus, to disentangle short- and long-run effects, we perform the frequency domain Granger causality test of Breitung and Candelon (2006) and Table 2 present the results.

Table 2 reports the test statistics, for some frequencies, $\omega$,(which are expressed as a fraction of $\pi$ ) in the interval $(0, \pi)$. The frequency, $\omega$, can be translated into a cycle or periodicity of $\mathrm{T}$ weeks by $\mathrm{T}=2 \pi / \omega$, where $\mathrm{T}$ is the length of the period (in this study represents week). High frequencies correspond to short periods and vice versa.

The results of frequency domain Granger causality tests, presented in Table 2, support the results of traditional Granger causality test. However, frequency domain analysis provides much clearer and more accurate details of the directions and strengths of causalities between the variables in different frequencies, which have never been given before. Therefore, by decomposing the causality into different frequencies, we will have a much deeper understanding of causal relationships between financial markets of Turkey.

For example, traditional Granger causality test results indicate that stock prices Granger cause both EURO and U.S. Dollar exchange rates. Frequency domain Granger causality tests results support these results and also 
indicate that stock prices cause EURO exchange rate both in medium and long-terms and U.S. Dollar in both short and medium-terms. First, we see that stock prices have significant causal effects on EURO exchange rates at both medium (frequency $\omega>2.00$ ( 4 weeks)) and long-terms (frequency $\omega<0.05$ (125 weeks)). But, there is no causality running from EURO to stock prices. These findings suggest that stock prices have connections with EURO exchange rates at different frequencies. Also, stock prices Granger cause U.S. Dollar at frequencies greater than 1.39, which correspond to short-and medium terms $(1<\omega<1.5$ (4 and 6 weeks)). On the other hand, U.S. Dollar Granger causes stock prices only in the short-run; that is in high frequencies. Thus, considering the EURO exchange rates, the results support the predictions of portfolio balance approach during the sample period. But, considering U.S. Dollar exchange rate, the results are mixed and provide evidences of supporting both approaches. According to Tsai (2012), there is a possible explanation for the different results of the direction of the causal relationship between stock price and exchange rate, since the portfolio balance effect should not exist every time and everywhere. We know that if the stock market of a country is not volatile, there will be no full absorption of inflows of the foreign capital by stock market. In this case, the indirect influence on exchange rate may then not exist. On the other hand, if the opportunity of profit is obvious and causes the considerable quantities of foreign capital to enter or leave the stock market, the obvious capital inflow or outflow will occur, and significant influence on exchange rate may be found. Therefore, during normal times if there is no obvious capital inflow or outflow, only the international trading effect will exist in the relationship between these two markets. However, during financial crises or bubbles in stock markets, profit opportunity occurs and causes significant amount of foreign capital to enter or leave the stock markets as has been the case mostly following the 2002 general elections, which is the AKP era. Sooner the later, this causes the currencies to depreciate or appreciate. In such a case, we expect a negative relationship between stock prices and exchange rates.

Second, the stock prices Granger cause interest rates at low level of frequencies implying that there exists medium-and long-term causality running from stock prices to interest rates; but no causality from interest rates to stock prices at any frequencies. These findings don't support the generally accepted notion for the causality running from interest rate to stock price. In other words, this finding provides some evidence to some critics claims the conventional wisdom of interest rate causality on stock prices. When the stock prices fall, the capital, especially speculative short-term capital flows, flows out of the country causing pressure on the exchange rate and increase the volatility of market. To stabilize foreign exchange rate market, interest rate is raised.

Third, there is a bidirectional causality between EURO exchange rates and interest rates. EURO exchange rates Granger cause interest rates at low frequencies $(\omega<0.05)$ that is in long-run; but, interest rates Granger cause EURO exchange rates in the short-run $(\omega>2.00$ ( 3 weeks). Therefore, based on the findings of study, we can conclude that the empirical results support the predictions of the Mundell-Fleming model in the long-run. On the other hand, the results validate the implications of the Dornbusch and portfolio balance model in the short-run. As explained in Hacker et al. (2012), in the Mundell-Fleming model if there is a sufficiently-high capital mobility, when there is a fall in the interest rate caused by a monetary or fiscal disturbance in the short-run, there will be an adjustment-period of increases in the exchange rate, implying a negative Granger causality from the interest rate differential to the exchange rates. On the other hand, in the Dornbusch and portfolio balance model, this adjustment period of decreases in the exchange rate implies positive Granger causality from the exchange rates to the interest rate differential.

\section{Conclusion}

In this study, we investigate the volatility spillovers between the foreign exchange, stock and money markets in Turkey. The results of the study show that there are spillovers from stock market returns to interest rates and EURO exchange rate both in the mid and long-runs, to U.S. Dollar both in short and medium-runs and from U.S. Dollar to stock market returns in the short-run. Thus, for regarding the EURO exchange rate, the results mostly support the portfolio balance view of the relationships between exchange rates and stock prices. But, for regarding U.S. Dollar exchange rate, the results are mixed. Also, we got some evidence of Granger causality running from EURO exchange rate to interest rates in the long-run and from interest rates to EURO exchange rate in the short-run. On other hand, there is no evidence of spillovers from EURO exchange rate and interest rates to stock market returns. Based on these results, we can conclude that there are certain degree of interdependence and volatility spillovers among the financial markets of Turkey, which have serious policy implications.

First of all, the results indicate that stock prices in Turkey can be used to predict movements of the EURO exchange rate both in medium and long-runs and that of U.S. Dollar exchange rate in short and medium-runs. Further, the U.S. Dollar exchange rate can be used to predict the movements of stock prices at short-run. Therefore, the participants of foreign exchange market can develop strategies to make profit from foreign 
exchange transactions by using stock prices to predict the movements of the EURO exchange rate both in medium and long-runs. However, the participants of the stock market can develop strategies to make profit by using the U.S. Dollar exchange rate to predict stock prices only in the short-run. Moreover, Turkish government can establish some policies that contributes to strengthen financial market transparency and accountability. Developing such policies obviously will help to prevent volatility in the stock prices as well as the erratic movements of the currency value in the foreign exchange market. Further, the above results provide mixed evidence for the validity of the traditional approach or portfolio approach in relation to the relationship between exchange rates and stock prices in Turkey.

This paper investigated the short, medium and long-run volatility spillovers between interest rates and exchange rates to provide some evidence to see if the high interest rate policy was appropriate for stabilizing foreign exchange rates. Based on the findings of study, we may conclude that tight monetary policy and subsequent rise in interest rates are not effective in stabilizing U.S. Dollar exchange rates in medium and long-runs; but, it can be used to stabilize the EURO exchange rates only in the short-run. When this conclusion is taken in consideration together with the high economic cost associated with keeping interest rates high for an extended time period, one may rightfully question the appropriateness of tight monetary policy during the financial markets turmoil, especially in exchange rates markets. Therefore, policy makers of the Turkish economy should be cautious in using interest rates to stabilize exchange rates markets, especially U.S. Dollar exchange rates market, since it has only short term implication on EURO exchange rates market.

Unlike to the generally accepted notion for the causality running from interest rate to stock price, the results of study indicate that there is a unidirectional causality running from stock prices to interest rates both in medium-and long-runs in Turkey, probably resulting from the fact that the booming stock market and phenomenal over-subscription of new issues might have impounded pressure on liquidity and thus caused interest rate movements. Also, we know that most of the investors of stock market of Turkey is consist of foreign investors. Therefore, for Turkey, controlling the interest rates will not ensure benefit to country's stock exchange through demand pull away of more investors in share market and supply push away of more extensional investment of companies. Also, to increase the interest of the foreign investors investing into stock market, first thing the authorities should do is to stabilize the foreign exchange rate markets of Turkey.

So, based on the results of frequency domain causality tests, it is fair to conclude that stock market in Turkey is leading the both money and exchange rate markets. Thus, to increase the interest of the foreign investors investing into stock market, the authorities should take into account bidirectional causality between stock and exchange rate markets.

\section{References}

Abdalla, I. S., \& Murinde, V. (1997). Exchange rate and stock price interactions in emerging financial markets: Evidence on India, Korea, Pakistan and Philippines. Applied Financial Economics, 7(1), 25-35. http://dx.doi.org/10.1080/096031097333826

Alam, M., \& Uddin, G. S. (2009). Relationship between interest rate and stock price: Empirical evidence from developed and developing countries. International Journal of Business and Management, 4(3), 43-51. http://dx.doi.org/10.5539/ijbm.v4n3p43

Andreou, E., Matsi, M., \& Savvides, A. (2013). Stock and foreign exchange market linkages in emerging economies. Journal of International Financial Markets, Institutions \& Money, 27, 248-268. http://dx.doi.org/10.1016/j.intfin.2013.09.003

Arango, L. E., Gonzalez, A., \& Posada, C. E. (2002). Returns and interest rate: A nonlinear relationship in the Bogota Stock Market. Applied Financial Economics, 12(11), 835-842. http://dx.doi.org/10.1080/09603100110094493

Arouri, M. E. H., Jouini, J., \& Nguyen, D. K. (2011). Volatility spillovers between oil prices and stock sector returns: Implications for portfolio management. Journal of International Money and Finance, 30(7), 1387-1405. http://dx.doi.org/10.1016/j.jimonfin.2011.07.008

Bahmani-Oskooee, M., \& Sohrabian, A. (1992). Stock Prices and the effective exchange rate of the dollar. Applied Economics, 24(4), 459-464. http://dx.doi.org/10.1080/00036849200000020

Bhattacharya, B., \& Mukherjee, J. (2003). Causal Relationship Between Stock Market and Exchange Rate. Foreign Exchange Reserves and Value of Trade Balance: A Case Study for India. The Fifth Annual Conference on Money and Finance in the Indian Economy (pp. 1-24). India. 
Baig, T., \& Goldfajn, I. (2002). Monetary policy in the aftermath of currency crises: The case of Asia. Review of International Economics, 10(1), 92-112. http://dx.doi.org/10.1111/1467-9396.00320

Bonga-Bonga, L., \& Hoveni, J. (2013). Volatility spillovers between the equity market and foreign exchange market in South Africa in the 1995-2010 period. South African Journal of Economics, 81(2), 260-274. http://dx.doi.org/10.1111/saje.12001

Breitung, J., \& Candelon, B. (2006). Testing for short- and long-run causality: A frequency domain approach, Journal of Econometrics, 132(2), 363-378. http://dx.doi.org/doi:10.1016/j.jeconom.2005.02.004

Chinn, M. D., \& Meredith, G. (2004). Monetary policy and long-horizon uncovered interest rate parity. IMF Staff Papers, 51(3), 409-430. Retrieved from https://www.imf.org/External/Pubs/FT/staffp/2004/03/pdf/chinn.pdf

Choi, I., \& Park, D. (2008). Causal relation between interest and exchange rates in the Asian currency crisis. Japan and the World Economy, 20(3), 435-452. http://dx.doi.org/10.1016/j.japwor.2007.01.003

Ciner, C. (2011a). Information transmission across currency futures markets: Evidence from frequency domain tests. International Review of Financial Analysis, 20(3), 134-139. http://dx.doi.org/10.1016/j.irfa.2011.02.010

Ciner, C. (2011b). Eurocurrency interest rate linkages: A frequency domain analysis. International Review of Economics \& Finance, 20(4), 498-505. http://dx.doi.org/10.1016/j.iref.2010.09.006

Croux, C., \& Reusens, P. (2013). Do stock prices contain predictive power for the future economic activity? A Granger causality analysis in the frequency domain. Journal of Macroeconomics, 35, 93-103. http://dx.doi.org/10.1016/j.jmacro.2012.10.001

Dekle, R., Hsiao, C., \& Wang, S. (2002). High interest rates and exchange rate stabilization in Korea, Malaysia, and Thailand: An empirical investigation of the traditional and revisionist views. Review of International Economics, 10(1), 64-78. http://dx.doi.org/10.1111/1467-9396.00318

Ding, M., Chen, Y., \& Bessler, S. L. (2006). Granger causality: Basic theory and application to neuroscience. In B. Schelter, M. Winterhalder, \& J. Timmer, (Eds.), Handbook of Time Series Analysis: Recent Theoretical Developments and Applications (pp. 437-460). Wiley. http://dx.doi.org/10.1002/9783527609970.ch17

Fedorova, E., \& Saleem, K. (2010). Volatility spillovers between stock and currency markets: Evidence from emerging Eastern Europe. Czech Journal of Economics and Finance, 60(6), 519-533. Retrieved from http://journal.fsv.cuni.cz/storage/1199_str_519_533_-_fedorova.pdf

Geweke, J. (1984). Inference and causality in economic time series models. Handbook of Econometrics, 2, 1101-1144. http://dx.doi.org/10.1016/S1573-4412(84)02011-0

Ghosh, A., \& Phillips, S. (1998). Inflation, disinflation, and growth. IMF Working Paper, (98/68), 1-44. http://dx.doi.org/10.5089/9781451961188.001

Giovannini, A., \& Jorion, P. (1987). Interest rates and risk premia in the stock market and in the foreign exchange market. Journal of International Money and Finance, 6(1), 107-123. http://dx.doi.org/10.1016/0261-5606(87)90016-7

Granger, C. W. J. (1969). Investigating causal relations by econometric models and cross-spectral methods. Econometrica, 37(3), 424-438. http://dx.doi.org/10.2307/1912791

Granger, C. W. J., \& Lin, J. L. (1995). Causality in the long Run, Econometric Theory, 11(3), 530-536. http://dx.doi.org/10.1017/S0266466600009397

Hacker, R. S., Kim, H., \& Månsson, K. (2012). The relationship between exchange rates and interest rate differentials: A wavelet approach. The World Economy, 35(9), 1162-1185. http://dx.doi.org/10.1111/j.1467-9701.2012.01466.x

Hamrita, M. E., \& Trifi, A. (2011). The relationship between interest rate, exchange rate and stock price: A wavelet analysis. International Journal of Economics and Financial Issues, 1(4), 220-228. Retrieved from http://www.econjournals.com/index.php/ijefi/article/view/47/pdf

Harasty, H., \& Roulet, J. (2000). Modeling stock market returns. Journal of Portfolio Management, 26(2), 33-46. http://dx.doi.org/10.3905/jpm.2000.319747

Hashemzadeh, N., \& Taylor, P. (1988). Stock prices, money supply, and interest rates: The question of causality, Applied Economics, 20(12), 1603-1611. http://dx.doi.org/10.1080/00036848800000091 
Hosoya, Y. (2001). Elimination of third series effect and defining partial measures of causality. Journal of Time Series Analysis, 22(5), 537-554. http://dx.doi.org/10.1111/1467-9892.00240

Joseph, A., Suresh, K. G., \& Garima, S. (2015). Is the causal nexus between agricultural commodity futures and spot prices asymmetric? Evidence from India. Theoretical Economics Letters, 5, 285-295. http://dx.doi.org/10.4236/tel.2015.52034

Kanas, A. (2000). Volatility spillovers between stock returns and exchange rate changes: International evidence. Journal of Business Finance \& Accounting, 27(3-4), 447-467. http://dx.doi.org/10.1111/1468-5957.00320

Krätschell, K., \& Schmidt, T. (2012). Long-run trends and short-run fluctuations - what establishes the correlation between oil and food prices? Ruhr Economic Papers, (357), 1-21. http://dx.doi.org/10.2139/ssrn.2123084

Kumar, M. (2010). Causal relationship between stock price and exchange rate: Evidence from India. International Journal of Economic Policy in Emerging Economies, 3(1), 85-101. http://dx.doi.org/10.1504/IJEPEE.2010.032797

Kutty, G. (2010). The relationship between exchange rates and stock prices: The case of Mexico. North American Journal of Finance and Banking Research, 4(4), 1-12. Retrieved from http://globip.com/articles/northamerjournal-vol4-article1.pdf

Ma, C. K., \& Kao, G. W. (1990). On exchange rate changes and stock price reactions. Journal of Business Finance \& Accounting, 17(3), 441-449. http://dx.doi.org/10.1111/j.1468-5957.1990.tb01196.x

Mishra, A. K. (2004). Stock market and foreign exchange market in India: Are they related? South Asia Economic Journal, 5(2), 209-232. http://dx.doi.org/10.1177/139156140400500202

Mok, H. M. K. (1993). Causality of interest rate, exchange rate and stock prices at stock market open and close in Hong Kong. Asia Pacific Journal of Management, 10(2), 123-143. http://dx.doi.org/10.1007/BF01734274

Muhammad, N., \& Rasheed, A. (2002). Stock Prices and Exchange Rates: Are they Related? Evidence from South Asian Countries. The Pakistan Development Review, 41(4), 535-550. Retrieved from http://www.pide.org.pk/pdf/PDR/2002/Volume4/535-550.pdf

Mukherjee, T. K., \& Naka, A. (1995). Dynamic relations between macroeconomic variables and the Japanese stock market: An application of a vector error correction model. The Journal of Financial Research, 18(2), 223-237. http://dx.doi.org/10.1111/j.1475-6803.1995.tb00563.x

Morales, L. N. (2008). Volatility spillovers between equity and currency markets: Evidence from major Latin American countries. Latin American Journal of Economics-formerly Cuadernos de Economía, 45(132), 185-215. Retrieved from http://www.economia.puc.cl/docs/132nieva.pdf

Mozumder, N., Vita, G., Kyaw, K. S., \& Larkin, C. (2015). Volatility spillover between stock prices and exchange rates: New evidence across the recent financial crisis period. Economic Issues, 20(1), 43-64. Retrieved from http://www.economicissues.org.uk/Files/2015/115Mozumder.pdf

Nieh, C., \& Lee, C. (2001). Dynamic relationship between stock prices and exchange rates for G-7 countries. The Quarterly Review of Economics and Finance, 41(4), 477-790. http://dx.doi.org/10.1016/S1062-9769(01)00085-0

Ong, L. L., \& Izan, H. Y. (1999). Stock and currencies: Are they related?. Applied Financial Economics, 9(5), 523-532. http://dx.doi.org/10.1080/096031099332186

Park, Y. C., Chung, C. S., \& Wang, Y. (1999). Exchange rate policies in Korea: Has exchange rate volatility increased after the crisis? KIEP Working Paper, (99-33), 1-63. Retrieved from https://www.kiep.go.kr/include/filedown.jsp?fname=WOPA199933.pdf\&fpath=Pub0201\&NO=131485\&F $\mathrm{NO}=326$

Rahman, L., \& Uddin J. (2009). Dynamic relationship between stock prices and exchange rates: Evidence from three South Asian countries. International Business Research, 2(2), 167-174. http://dx.doi.org/10.5539/ibr.v2n2p167

Ross, S. A. (1989). Information and Volatility: The No-Arbirtrage Martingale Approach to Timing and $\begin{array}{lllll}\text { Resolution Irrelevancy. Journal of } & \text { Finance, } & 44(1), & \text { 1-17. }\end{array}$ http://dx.doi.org/10.1111/j.1540-6261.1989.tb02401.x 
Seth, A. K. (2010). A MATLAB toolbox for Granger causal connectivity analysis. Journal of Neuroscience Methods, 186(2), 262-273. http://dx.doi.org/ 10.1016/j.jneumeth.2009.11.020

Shanken, J. (1990). Intertemporal asset pricing: An empirical investigation. Journal of Econometrics, 45(1-2), 99-120. http://dx.doi.org/10.1016/0304-4076(90)90095-B

Smith, C. E. (1992). Stock Market and the exchange Rate: A multi-country approach. Journal of Macroeconomics, 14(4), 607-629. http://dx.doi.org/10.1016/0164-0704(92)90003-Q

Solnik, B. (1987). Using financial prices to test exchange rate models: A note. Journal of Finance, 42(1), 141-49. http://dx.doi.org/10.1111/j.1540-6261.1987.tb02555.x

Tiwari, A. K. (2012). An empirical investigation of causality between producers' price and consumers' price indices in Australia in frequency domain. Economic Modelling, 29(5), 1571-1578. http://dx.doi.org/10.1016/j.econmod.2012.05.010

Walid, C., Chaker, A., Masood, O., \& Fry, J. (2011). Stock market volatility and exchange rates in emerging countries: A Markov-state switching approach. Emerging Markets Review, 12(3), 272-292. http://dx.doi.org/10.1016/j.ememar.2011.04.003

Wong, W., Khan, H., \& Du, J. (2005). Money, interest rate, and stock prices: New evidence from Singapore and the United States. U21Global Working Paper No, (007/2005), pp. 1-26. http://dx.doi.org/10.2139/ssrn.1607605

Wongbangpo, P., \& Sharma, S. C. (2002). Stock market and macroeconomic fundamental dynamic interactions: ASEAN-5 countries. Journal of Asian Economics, 13(1), 27-51. http://dx.doi.org/10.1016/S1049-0078(01)00111-7

Yao, F., \& Hosoya, Y. (2000). Inference on one-way effect and evidence in Japanese macroeconomic data. Journal of Econometrics, 98(2), 225-255. http://dx.doi.org/doi:10.1016/S0304-4076(99)00084-6

\section{Note}

This study was presented in 4th International M-Sphere Conference, Dubrovnik, Croatia, October 22-24, 2015.

\section{Copyrights}

Copyright for this article is retained by the author(s), with first publication rights granted to the journal.

This is an open-access article distributed under the terms and conditions of the Creative Commons Attribution license (http://creativecommons.org/licenses/by/3.0/). 